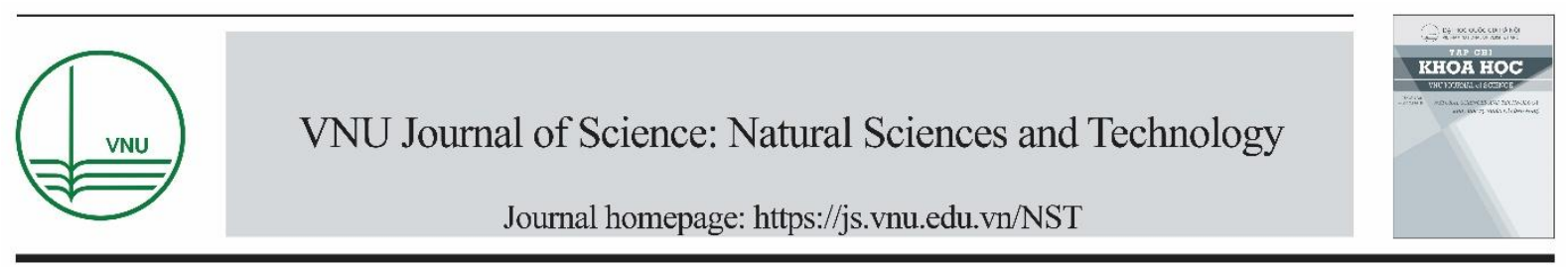

Original Article

\title{
Ophiorrhiza fangdingii (Rubiaceae), a New Record for the Flora of Vietnam
}

\author{
Pham Van Quang ${ }^{1}$, La Thi Thuy ${ }^{1}$, Nguyen Trung Thanh ${ }^{1}$, Do Van Truong, ${ }^{2, *}$ \\ ${ }^{1}$ Faculty of Biology, VNU University of Science, 334 Nguyen Trai, Thanh Xuan, Hanoi, Vietnam \\ ${ }^{2}$ Department of Biology, Vietnam National Museum of Nature, Vietnam Academy of Science \& \\ Technology, 18 Hoang Quoc Viet, Hanoi, Vietnam
}

Received 20 November 2018

Revised 11 March 2019; Accepted 14 March 2019

\begin{abstract}
Ophiorrhiza fangdingii H.S. Lo, a species endemic to Guangxi, China, is newly reported for the flora of Vietnam. In addition to the information on ecology, phenology and taxonomic notes, the morphological characters of the capsule are firstly described based on the specimens collected in Vietnam.
\end{abstract}

Keywords: New record, Ophiorrhiza fangdingii, Rubiaceae, Vietnam.

\section{Introduction}

The genus Ophiorrhiza L. (Rubiaceae) comprises ca. 200-300 species and mainly distributed in wet tropical forests of South-East Asia and extends from Sri Lanka and Eastern India to China, Japan, and Southeast through Malesia and Fiji to the society Island [1, 2]. Some species of Ophiorrhiza are reported to

\footnotetext{
*Corresponding author.

Email address: dovantruong_bttn@yahoo.com https://doi.org/10.25073/2588-1140/vnunst.4828
}

possess medicinal properties both in traditional and conventional medicines, e.g. O. mungos L. and $O$. pumila Champ. ex Benth. [3, 4] or introduced in the gardens for its ornamental value [5].

Ophiorrhiza is a notably species-rich, taxonomically complicated genus [1] that has been little-studied by taxonomists and is poorly known particularly in Southeast Asia [2]. Although several taxonomic treatments of the genus were published for geographical areas, i.e. Pacific [1], India [5], China [2, 6, 7], Indochina [8], a worldwide monographic study 
has yet to be attempted. Within South-East Asia, China is considered as one of the diversity centers of Ophiorrhiza, ca. 70 species are recorded for the country [2], followed by India, with 47 species are recorded [5]. In Vietnam, 13 species and one variety are counted $[8,9]$.

While revising taxonomy of the genus Ophiorrhiza from Vietnam, we found out an interesting specimen at VNMN herbarium that collected from Hoang Lien-Van Ban Nature Reserve, Northern Vietnam. Reexamination of the specimens and studies on the protologues and type specimens of previously known species revealed that this specimen completely matches with Ophiorrhiza fangdingii H.S.Lo, a species endemic to Guangxi province, SouthEastern China [6, 7]. Therefore, Ophiorrhiza fangdingii is here reported as a new record for the flora of Vietnam. Furthermore, Lo (1990) did not describe capsule in the protologue of $O$. fangdingii which is here done based on the specimens collected from Vietnam.

\section{Material and methods}

Taxonomic treatments and protologues of previously described Ophiorrhiza species from Indo-china [8, 9] and neighbouring floristic regions, i.e. the flora China [2, 6, 7], the flora of India [5], and the flora of Thailand [10] were reviewed.

The macromorphological features were studied based on the specimen sheets and notes in the field, micromorphological characters were analysed and photographed using an optical microscope (Stemi DV4, LEICA S8 AP0). The morphological characters of studied specimens were compared with previously described species of Ophiorrhiza available from major herbaria: BNU, GXMI, HITBC, HN, HNU, IBK, IBSC, K, KUN, P, PE and VNMN.

\section{Taxonomic treatment}

Ophiorrhiza fangdingii H.S.Lo in S.Y.Jin \& Y.L.Chen, Cat. Type Spec. Herb. China (Suppl). 190. 1999. (Figures $1 \& 2$ ).

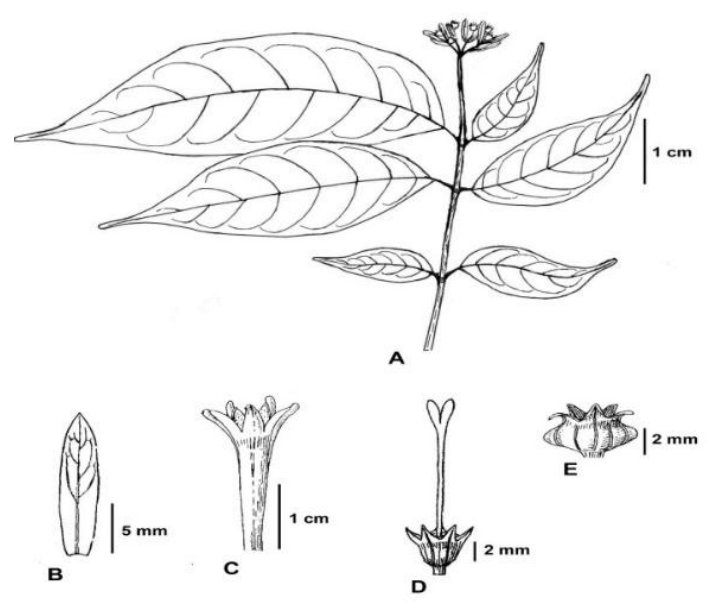

Figure 1. Ophiorrhiza fangdingii - A. Branch with a terminal inflorescence; B. Bracteole; C. Corolla; D. Hypanthium and pistil; E. Capsule. Drawn from the specimen T.V. Do 162 (VNMN) by Pham Van Quang.

Herbaceous, weak, ascending, to $20 \mathrm{~cm}$ tall, stems subterete, drying darkness brown, glabrescent. Stipule caducous. Petiole 5-15 mm long, glabrous. Leaves in unequal pairs, leaf blade drying papery, oblong-ovate or oblonglanceolate, larger ones $2.5-7 \times 1.5-3 \mathrm{~cm}$, smaller ones $1.5-4 \times 1.5-2 \mathrm{~cm}$, adaxially leaden gray, abaxially pale with brown to reddish veins, glabrous on both surfaces, base subcuneate and somewhat inequilateral, apex apiculate to acuminate, margins entire, secondary veins pinnate, 5-8(-10) pairs, merged at margin. Inflorescences terminal, capitatelike, 4-5-flowered; penducle 1.5-2 cm long, glabrous, axes very short, helicoid; bracteoles linear or narrowly lanceolate, $10-16 \times 2-3.5$ $\mathrm{mm}$, pinnate veins prominent, obtuse, costate. Flowers distylous. Pedicels 5-6 mm long. Calyx glabrous, hypanthium turbinate, $1.5-2.5 \mathrm{~mm}$ long, unequally 5-lobed, lobes linear or 
narrowly lanceolate, 2-2.5 mm long. Corolla white, funnel-form, $2-2.2 \mathrm{~cm}$ long, outside glabrous, above middle inside white villous; lobes dorsally narrowly winged, wing extending into very short horn. Stamens 5, inserted near throat to bellow middle of corolla tube, included; filaments reduced to well developed; anthers dorsifixed near middle or base. Ovary 2-celled, ovules numerous in each cell on placentas attaches from middle to base of septum; stigmas 2-lobed, linear to subglobose. Capsule obovoid to oblate, 2-4 mm diameter, strongly laterally compressed perpendicular to septa, loculicidally dehiscent across top and sometimes along sides, with calyx lobes persistent; seeds numerous, small, angled to rhomboid, areolate to alveolate.

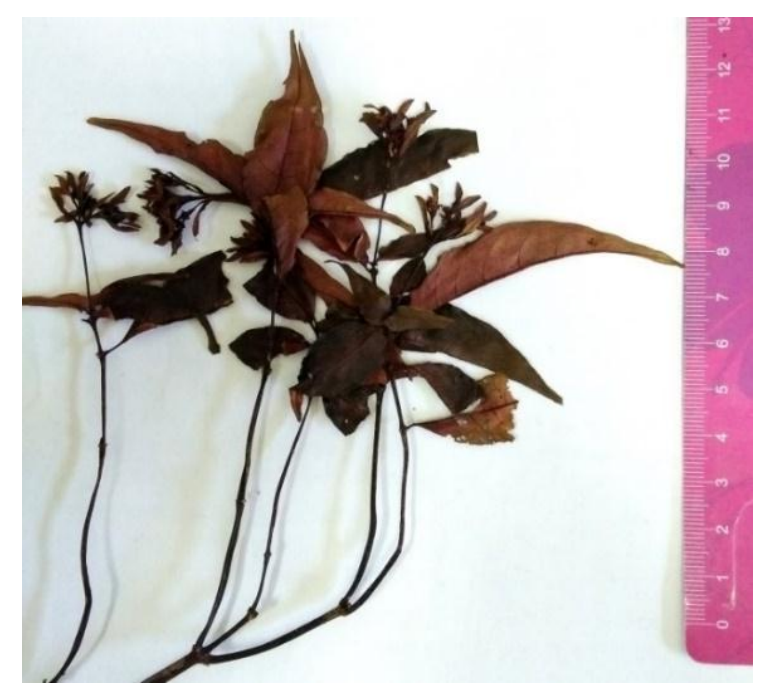

Figure 2. Morphology of Ophiorrhiza fangdingii (T.V.Do 162 at VNMN).

Type: CHINA: Guangxi: Napo, Badu, Longhua, 28 January 1984, D.Fang \& Z.G. Wang 78434 (GXMI!)

Ecology and Phenology: Ophiorrhiza fangdingii grows on humidity places under mixed broad leaf and needle leaf forest, with dominant plants of Fokienia hodginsii A.Henry \& H.H.Thomas, Calocedrus ssp, Exbucklandia populnea (R.Br. ex Griff.) R.W.Br., Rhodoleia parvipetala Tong, Eriobotrya ssp, ca. 1200$1800 \mathrm{~m}$ alt. Flowering and fruiting are observed from December to March later.

Distribution: CHINA (Napo, Guangxi), new to VIETNAM (Van Ban, Lao Cai).

Additional specimens examined: CHINA. Guangxi, Napo, Baidu, Nonghua, 15 March 1986, alt. 1250m, D.Fang \& D.H.Yan 79860 (GXMI 029493); 27 March 2014, L.Wu 4336 (BNU 0015346). VIETNAM: Lao Cai. Van Ban, Hoang Lien-Van Ban Nature Reserve, 22 January 2018, 21 ${ }^{\circ} 57^{\prime} 19.02^{\prime \prime} \mathrm{N}, 104^{\circ} 04^{\prime} 34.12^{\prime \prime} \mathrm{E}$; alt. $1812 \mathrm{~m}$, T.V.Do 162 (VNMN).

Notes: Ophiorrhiza fangdingii is clearly different from the rest of Ophiorrhiza in Vietnam by having linear or narrowly lanceolate bracteoles. In comparison to the Chinese population, the Vietnamese populations of Ophiorrhiza fangdingii have shorter petioles, longer peduncles, and the abaxial leaf surface is much brown to reddish than that of the Chinese populations.

\section{Acknowledgements}

We would sincerely acknowledge the curators of the following herbaria: BNU, GXMI, HITBC, HN, HNU, IBK, IBSC, K, KUN, NIMM, P, PE and VNMN for their permission to work on Ophiorrhiza collections. Many thanks are expressed to Dr. Lei Wu from College of Forestry, Central South University of Forestry and Technology, Changha, China for sharing literature and knowledge of Ophiorrhiza. This study is financially supported by Vietnam Academy of Science and Technology. 


\section{References}

[1] S.P. Darwin, The Pacific species of Ophiorrhiza L. (Rubiaceae), Lyonia. 1 (1976) 47.

[2] C. Tao, C.M. Taylor, Ophiorrhiza in Flora of China, Science Press, Beijing \& Missouri Botanical Garden Press, St. Louis, Volume 19, 2011.

[3] G. Krishnakumar, K.B. Rameshkumar, S. Priya, K. Satheeshkumar, P.N. Krishnan, Estimation of camptothecin and pharmacological evaluation of Ophiorrhiza prostrata D. Don and Ophiorrhiza mungos L.,Asian Pacific Journal of Tropical Biomedicine. 2 (2012) 731.

[4] K. Saito, H. Sudo, M.Yamazaki, M. Koseki Nakamura, M. Kitajima, H. Takayama, N. Aimi, Feasible production of camptothecin by hairy root culture of Ophiorrhiza pumilla, Plant Cell Reports. 20 (2001) 271.
[5] D.B. Deb, D.C. Mondal, Taxonomic revision of the genus Ophiorrhiza L. (Rubiaceae) in Indian subcontinent Ophiorrhiza L. (Rubiaceae) in Indian subcontinent, Bulletin of the Botanical Survey India. 39 (1997) 148.

[6] H.S. Lo, Ophiorrhiza in Flora Republicae Popularis Sinicae, Science Press, Beijing, Volume 71(1), 1999, 110-174,

[7] H.S. Lo, Taxonomic revision of the Chinese species of Ophiorrhiza (Rubiaceae), Bulletin of Botanicial Research North-Eastern Forestry Institute. 10 (1990) 82.

[8] J. Pitard, Ophiorrhiza in Flore Generade de l'Indo-Chine, volume 3, Masson, Paris, 1923.

[9] H.H. Pham, OphiorrhizainAn Illustrated Flora of Vietnam, volume 3, Young Publishing House, Ho Chi Minh, 2003 (in Vietnamese)

[10] W.G. Craib, Caprifoliaceae \& Rubiaceaein Florae SiamensisEnumeratio, Siam Society, Bangkok, Volume 2(1), 1932, 253. 